\title{
OPTIMIZATION AND CHARACTERIZATION OF CHITOSAN-BASED NANOPARTICLES CONTAINING METHYLPREDNISOLONE USING BOX-BEHNKEN DESIGN FOR THE TREATMENT OF CROHN'S DISEASE
}

\author{
GANESH N. SHARMA ${ }^{*}$, C. H. PRAVEEN KUMAR ${ }^{2}$, BIRENDRA SHRIVASTAVA ${ }^{3}$, B. KUMAR ${ }^{4}$
}

*1,2,3Department of Pharmacology, School of Pharmaceutical Sciences, Jaipur National University, Jagatpura, Jaipur 302017, India, ${ }^{4}$ Ratnam Institute of Pharmacy, Pidathapolur (V), Muthukur (M), SPSR Nellore Dt. 524346, Andhra Pradesh, India

Email: praveenchembeti@gmail.com

Received: 23 Nov 2019, Revised and Accepted: 20 Dec 2019

\section{ABSTRACT}

Objective: The present research was designed to produce methylprednisolone containing chitosan-based nanoparticles using Box-Behnken Design (BBD) and Response Surface Methodology (RSM) for optimization.

Methods: Nanostructures were prepared using the ionic gelation method with screened process parameters. According to the design, methylprednisolone chitosan-based nanoparticles (MCSNPs) were optimized using factors like methylprednisolone concentration, stirring speed and temperature whereas particle size, zeta potential and \% encapsulation efficiency as responses. From the observed values of responses with confirmation location and desirability, the predicted values were very close to the observed values.

Results: Observed values for the optimized formulation have a particle size of $243 \pm 2.33 \mathrm{~nm}$ with an encapsulation efficiency of $79.3 \pm 7.2 \%$. Morphology of the particles using scanning electron microscopy reveals nearly spherical shaped particles. Methylprednisolone was released in vitro in a sustained manner for about $24 \mathrm{~h}$ in simulated colonic fluid $\mathrm{pH}$ 7, $\mathrm{pH} 7.8$ (Fasted state) and phosphate buffer $\mathrm{pH}$ 7.4, when compared to simulated colonic fluid at pH 6 (Fed state). Optimized MCSNPs followed Korsmeyer peppas kinetics with drug release mechanism as anomalous transport.

Conclusion: Application of Box-Behnken design and Response Surface Methodology using Design Expert software was successfully used in the optimization of methylprednisolone loaded chitosan-based nanoparticles with high encapsulation efficiency.

Keywords: Methylprednisolone, Chitosan, Tripolyphosphate, Crohn's disease, Response Surface Methodology

(C) 2020 The Authors. Published by Innovare Academic Sciences Pvt Ltd. This is an open-access article under the CC BY license (http://creativecommons.org/licenses/by/4.0/) DOI: http://dx.doi.org/10.22159/ijap.2020v12i2.36462. Journal homepage: https://innovareacademics.in/journals/index.php/ijap

\section{INTRODUCTION}

Methylprednisolone is a potent anti-inflammatory agent used in the short-term and long-term treatment of Crohn's disease (CD) [1, 2]. Methylprednisolone is BCS class-II drug with the least solubility and high permeability with many challenges for the scientists working on novel targeted drug delivery system [3]. Methylprednisolone has a maximum percentage of remission in CD when compared to ulcerative colitis [4-6].

In the present research, methylprednisolone nanoparticles were prepared to target the drug into the colon. For this intention, chitosan was selected as a polymer because of its biodegradability, biocompatibility and ability to sustain the drug release in colonic $\mathrm{pH}$ [7]. The presence of primary amine at $\mathrm{C}-2$ position of glucosamine residue made chitosan as an important polysaccharide for the fabrication of functional drug delivery. Ability of chitosan to release the drug in a sustained manner is because of the deprotonation of amines that undergo inter-polymer associations leading to film and gel formation [8, 9]. Ionic gelation method was used in the fabrication of MCSNPs due to the avoidance of organic solvents with less shear forces [10]. From the literature, it was found that methylprednisolone nanoparticles were prepared using albumin [11], inulin [12], cyclodextrin polymer [13] etc.

The present research was accomplished to optimize and characterize chitosan-based methylprednisolone nanoparticles using Box-Behnken design. The prepared methylprednisolone nanoparticles were filled in capsules, which were further coated with $\mathrm{pH}$-sensitive polymers like cellulose acetate phthalate and eudragit-S 100 using polyethylene glycol-300 as a plasticizer to keep chitosan safe in gastric $\mathrm{pH}$.

\section{MATERIALS AND METHODS}

\section{Materials}

Methylprednisolone was kindly gifted by SP Accure Labs, Hyderabad. Chitosan, Tripolyphosphate (TPP) and Phosphatidyl- choline were purchased from Sigma Aldrich, Mumbai. Eudragit S100, Cellulose acetate phthalate was obtained from Drugs India Hyderabad. Tris and Bovine serum albumin from Thermo Fisher Scientific, Hyderabad. Sodium phosphate dibasic, Sodium hydroxide, Dichloromethane, Potassium phosphate monobasic was obtained from New Himalaya Scientific Company, Nellore. All the chemicals used were of analytical grade.

Fabrication of blank chitosan nanoparticles using ionic gelation method

Chitosan (CS) solutions were prepared by dissolving chitosan in aqueous acetic acid according to the coded values in table 1 and formulation table 2. Tripolyphosphate (TPP) aqueous solutions were prepared according to the stated quantities and added dropwise to the chitosan solutions under stirring at $400 \mathrm{rpm}$ for $100 \mathrm{~min}$ using IKA stirrer for preparing chitosan nanoparticles (CSNPs). If necessary $\mathrm{pH}$ was adjusted to 4.5 using Mettler Toledo $\mathrm{pH}$ meter with $1 \mathrm{M}$ aqueous sodium hydroxide solution to neutralize the excess acid. Then CS-TPP suspension was ultrasonicated using PCI analytics ultrasonicator for $5 \mathrm{~min}$ to produce CSNPs with controlled sizes. CS-TPP suspension was vacuum filtered using Millipore vacuum pump and produced CSNPs were dried.

The technique was optimized by Design-Expert software using BoxBehnken design (BBD) with 13 runs, 3-factor, and 3-level as shown in table 1 . The design is suitable for investigating the quadratic response surface and constructing a second-order polynomial model. The dependent and independent variables with actual values were shown in the table. Temperature $\left(35^{\circ} \mathrm{C}\right), \mathrm{pH}(4.5)$ and stirring speed $(600$ rpm) was constant variables for preparing chitosan-based nanoparticles.

Fabrication of methylprednisolone loaded chitosan nanoparticles using ionic gelation method

By using the optimized factors of blank CSNPs, formulation parameters for preparing methylprednisolone CSNPs were 
identified and screened through BBD. The dependent and independent variables were shown in the table 3 . Thirteen batches were prepared according to the design as shown in table 4 and evaluated for particle size, zeta potential and entrapment efficiency
(\% EE). The concentrations of chitosan, tripolyphosphate and acetic acid were kept constant as per the optimized factors of blank CSNPs. The method of preparation is the same as the preparation of blank CSNPs.

Table 1: Variables with coded and actual values for box-behnken design (Formulation-blank CSNPs)

\begin{tabular}{|c|c|c|c|}
\hline Independent variables & Low & Medium & High \\
\hline Coded values & $(-1)$ & $(0)$ & $(-1)$ \\
\hline $\mathrm{A}=$ Chitosan $(\mathrm{mg} / \mathrm{ml})$ & 2 & 3.5 & 5 \\
\hline $\mathrm{B}=$ Tripolyphosphate $(\mathrm{mg} / \mathrm{ml})$ & 0.5 & 1.25 & 2 \\
\hline $\mathrm{C}=$ Acetic acid $(\mathrm{mg} / \mathrm{ml})$ & 0.2 & 0.5 & 0.8 \\
\hline \multicolumn{4}{|l|}{ Dependent variables constrains } \\
\hline \multicolumn{4}{|l|}{$\mathrm{Y} 1$ = Particle size (nm): Goal-Minimize } \\
\hline \multicolumn{4}{|l|}{ Y2 = Zeta potential (mV): Goal-In range } \\
\hline Y3= Poly dispersity Index: Goal-Minimize & & & \\
\hline
\end{tabular}

Table 2: Formulations showing factors optimized by box-behnken design, (formulation-blank CSNPs) (n=13)

\begin{tabular}{lll}
\hline Formulation code & $\begin{array}{l}\text { Factor-1 } \\
\text { chitosan (mg/ml) }\end{array}$ & $\begin{array}{l}\text { Factor-2 } \\
\text { tripolyphosphate (mg/ml) }\end{array}$ \\
\hline CNI-1 & 5 & 1.25 \\
CNI-2 & 2 & 2 \\
CNI-3 & 3.5 & 1.25 \\
CNI-4 & 2 & 1.25 \\
CNI-5 & 2 & 1.25 \\
CNI-6 & 3.5 & 2 \\
CNI-7 & 3.5 & 2 \\
CNI-8 & 5 & 0.5 \\
CNI-9 & 3.5 & 0.5 \\
CNI-10 & 3.5 & 0.5 \\
CNI-11 & 5 & 0.5 \\
CNI-12 & 5 & 2 \\
CNI-13 & 2 & 1.25 \\
\hline
\end{tabular}

Table 3: Variables with coded and actual values for box-behnken design, (formulation-methylprednisolone CSNPs)

\begin{tabular}{lll}
\hline Independent variables & Low & Medium \\
\hline Coded Values & $(-1)$ & $(0)$ \\
A=Methylprednisolone $(\mathrm{mg} / \mathrm{ml})$ & 0.5 & 0.75 \\
B=Stirring Speed (rpm) & 400 & 600 \\
C= Temperature $\left({ }^{\circ} \mathrm{C}\right)$ & 10 & 22.5 \\
Dependent variables Constrains & & \\
Y1 = Particle size (nm): Goal-Minimize & & \\
Y2 = Zeta potential (mV): Goal-Maximize & & \\
Y3= \% EE: Goal-Maximize & & \\
\hline
\end{tabular}

Table 4: Formulations showing factors optimized by Box-Behnken design, (Formulation-MCSNPs) (n=13)

\begin{tabular}{lll}
\hline Formulation code & $\begin{array}{l}\text { Factor-1 } \\
\text { methylprednisolone }(\mathbf{m g} / \mathbf{m l})\end{array}$ & $\begin{array}{l}\text { Factor-2 } \\
\text { stirring speed (rpm) }\end{array}$ \\
\hline MCSNP-1 & 1 & 400 \\
MCSNP-2 & 0.75 & 600 \\
MCSNP-3 & 1 & 600 \\
MCSNP-4 & 0.5 & 600 \\
MCSNP-5 & 0.75 & 400 \\
MCSNP-6 & 0.5 & 600 \\
MCSNP-7 & 1 & 800 \\
MCSNP-8 & 1 & 600 \\
MCSNP-9 & 0.5 & 400 \\
MCSNP-10 & 0.75 & 800 \\
MCSNP-11 & 0.5 & 800 \\
MCSNP-12 & 0.75 & 400 \\
MCSNP-13 & 0.75 & 800 \\
\hline
\end{tabular}

\section{Morphology of CSNPs and MCSNPs}

Morphology and shape analysis of optimized MCSNPs were evaluated using SEM (Hitachi S-4300 Microscope). The formulations were placed on the double-sided adhesive carbon tabs and adhered to aluminium stubs coated with gold/palladium alloy using Emscope sputter coating system at $20 \mu \mathrm{A}$ for 1 minute under argon gas.
Electronic beam at an accelerating voltage of $5-10 \mathrm{kV}$ was used at a working distance of 13-15 mm. Using similar conditions images were captured at several magnifications [14].

\section{Particle size and (polydispersity index) PDI}

Freshly prepared nanoparticles of methylprednisolone were diluted 200 times with deionized water and measured the particle size, PDI 
and zeta potential using Malvern zeta sizer nano (ZS90). Average particle size was measured by dynamic light scattering at an angle of $90^{\circ}$. The properties of dispersion and stability of nanoparticles were also measured using the same instrument. All the measurements were done in a triplicate at $25^{\circ} \mathrm{C}$ [15-18].

\section{Entrapment efficiency (\%EE)}

Amount of methylprednisolone encapsulated in the nanoparticles was determined by separating the free drug using ultracentrifugation (Remi centrifuge). The formulations were centrifuged at around $18,000 \mathrm{rpm}$ for $40 \mathrm{~min}$. The supernatant was collected and the concentration of methylprednisolone incorporated in the formulations was analyzed separately using Shimadzu UV Spectrophotometer at $242 \mathrm{~nm}[19,20]$.

$$
\% \mathrm{EE}=\frac{(\mathrm{Sa}-\mathrm{Sb})}{\mathrm{Sa}} * 100
$$

$\mathrm{S}_{\mathrm{a}}=$ Total amount of drug in the system, $\mathrm{S}_{\mathrm{b}}=$ Amount of drug in the supernatant after centrifugation.

\section{FT-IR studies for optimized formulation}

Cross-linking reaction between the phosphoric group of tripolyphosphate (TPP) and an amino group of chitosan was analyzed to confirm using Perkin Elmer Spotlight 200i FT-IR. Homogeneously dried formulation was used to prepare $\mathrm{KBr}$ pellet, where the powder was compressed under vacuum using a round flat face punch. Samples were scanned from about $4000-400 \mathrm{~cm}^{-1}$ [21].

\section{Powder X-ray diffraction (PXRD)}

Information regarding crystal lattice arrangements and the degree of crystallinity of optimized MCSNPs was analyzed using PXRD. To analyze the physical state, PXRD spectra of dried nanoparticles were recorded at room temperature using Arex X-ray diffractometer with a voltage of $3 \mathrm{Kv}, 5 \mathrm{Ma}$ current with a scanning speed of $40 / \mathrm{min}$. Samples were scanned from 0 to $600(2 \theta)$ range with a step interval of 0.1 seconds [22].

\section{In vitro drug release}

Drug release was performed in vitro using the dialysis bag method. Dialysis bags were soaked in deionized water overnight prior to the experiment. Nanoparticles dispersion of $2 \mathrm{ml}$ is placed in the dialysis bag of $2000 \mathrm{Da}$ and fixed two ends with the help of clamps. The bags were transferred into $250 \mathrm{ml}$ phosphate buffer $\mathrm{pH} 7.4$ and in simulated colonic fluid (Fed and Fasted state) kept at $35 \pm 0.5^{\circ} \mathrm{C}$ for the determination of drug release. Samples were withdrawn at a specified time intervals for about $24 \mathrm{H}$. At the predetermined time intervals $1 \mathrm{ml}$ of sample was withdrawn by adding the fresh buffer/fresh simulated colonic fluid. The samples were analyzed using UV spectrophotometry at $242 \mathrm{~nm}$. All the measurements were done in a triplicate [23]. By using various kinetic models mechanism of drug release was noted based on $\mathrm{R}^{2}$ and ' $n$ ' value.

\section{RESULTS AND DISCUSSION}

\section{Statistical analysis (Box-behnken design)}

The results of Box-Behnken design were analyzed and the utility of this statistical design resulted in providing considerable information to optimize the formulation. All the responses were fitted to a quadratic model and compatibility of the model was verified by ANOVA, lack of fit and co-efficient of determination $\left(\mathrm{R}^{2}\right)$. To optimize the responses, every response should be interconnected with each other and a most supportive zone must be required for every response to exclude bias. Desirability function was supported by much literature to optimize the multiple responses [24,25].

Blank chitosan nanoparticles were formulated to optimize the concentration of chitosan, TPP and acetic acid based on the dependent variables like particle size, zeta potential and polydispersity index (PDI). Results for the responses were shown in table 5. With an increase in the concentration of chitosan and TPP, particle size and zeta potential were increased and vice versa. PDI increased linearly with the increase in the concentration of acetic acid was in acceptance according to the literature [26-28]. P-Values for the responses $\mathrm{y}_{1}, \mathrm{y}_{2}, \mathrm{y}_{3}$ was found to be $0.002,0.001,0.034$ Hence, the quadratic model is best fitted for all the responses with ${ }^{*} \mathrm{P}<0.05$. Table 6 shows a summary of the regression analysis of all the responses. Polynomial equations 1, 2, 3 for $\mathrm{Y}_{1}, \mathrm{Y}_{2}, \mathrm{Y}_{3}$ explains the significant model terms with ${ }^{*} \mathrm{P}<0.05$. The variables with negative values represent negative effects on responses. Based on the desirability function, interaction effects between two factors and confirmation location was predicted using 2D contour and 3D response surface graphs shown in table 7 and fig. 1-4. Among the responses, $Y_{1}$ and $Y_{3}$ were set in minimize, whereas $Y_{2}$ in range. Confirmation location for the optimized formulation was achieved at $\mathrm{A}=3.30 \mathrm{mg} / \mathrm{ml}, \mathrm{B}=1.36 \mathrm{mg} / \mathrm{ml}, \mathrm{C}=0.2 \mathrm{mg} / \mathrm{ml}$ with $Y_{1}=238.64$ $\mathrm{nm}, \mathrm{Y}_{2}=30 \mathrm{mV}$ and $\mathrm{Y}_{3}=0.175$. Observed values for the confirmation location were close to the predicted values showing that Box-Behnken Design can be considered being the best tool in formulating methylprednisolone chitosan nanoparticles.

Table 5: Optimization of blank chitosan-based nanoparticles using ionic gelation technique: (Formulation-blank CSNPs) n=13

\begin{tabular}{llll}
\hline Formulation code & $\begin{array}{l}\text { Response-1 }\left(\mathbf{Y}_{\mathbf{1}}\right) \\
\text { particle size }(\mathbf{n m})\end{array}$ & $\begin{array}{l}\text { Response-2 }\left(\mathbf{Y}_{\mathbf{2}}\right) \\
\text { zeta potential }(\mathbf{m V})\end{array}$ & $\begin{array}{l}\text { Response-3 }\left(\mathbf{Y}_{\mathbf{3}}\right) \\
\text { PDI }\end{array}$ \\
\hline CNI-1 & $359 \pm 6.31$ & $59.19 \pm 0.69$ & $0.231 \pm 0.003$ \\
CNI-2 & $196 \pm 4.34$ & $21.13 \pm 1.02$ & $0.186 \pm 0.002$ \\
CNI-3 & $245 \pm 6.45$ & $33.43 \pm 0.53$ & $0.193 \pm 0.001$ \\
CNI-4 & $180 \pm 7.32$ & $19.32 \pm 0.49$ & $0.173 \pm 0.004$ \\
CNI-5 & $183 \pm 8.12$ & $20.11 \pm 1.16$ & $0.197 \pm 0.002$ \\
CNI-6 & $293 \pm 9.11$ & $39.61 \pm 0.59$ & $0.216 \pm 0.004$ \\
CNI-7 & $289 \pm 8.13$ & $35.51 \pm 0.89$ & $0.177 \pm 0.003$ \\
CNI-8 & $329 \pm 6.21$ & $49.12 \pm 1.32$ & $0.217 \pm 0.002$ \\
CNI-9 & $231 \pm 6.34$ & $31.21 \pm 1.11$ & $0.232 \pm 0.003$ \\
CNI-10 & $219 \pm 7.22$ & $26.17 \pm 1.34$ & $0.189 \pm 0.003$ \\
CNI-11 & $392 \pm 3.45$. & $62.21 \pm 0.67$ & $0.206 \pm 0.002$ \\
CNI-12 & $347 \pm 5.45$ & $52.31 \pm 0.78$ & $0.181 \pm 0.006$ \\
CNI-13 & $173 \pm 6.34$ & $16.12 \pm 0.65$ & $0.192 \pm 0.003$ \\
\hline
\end{tabular}

*Data from each response is presented in mean \pm SD $(n=3)$

Table 6: Summary of regression analysis of the responses (CSNPs)

\begin{tabular}{lllll}
\hline Quadratic model & $\mathbf{R}^{\mathbf{2}}$ & Adjusted R & SD & Adequate Precision \\
\hline Response-1 particle size $(\mathrm{nm})$ & 0.99 & 0.98 & 9.57 & 27.19 \\
Response-2 zeta potential (mV) & 0.99 & 0.99 & 0.51 & 98.00 \\
Response-3 PDI & 0.99 & 0.97 & 0.0028 & 24.36 \\
\hline
\end{tabular}




\section{Polynomial equations with intercept and coded factors (CSNPs)}

$\mathrm{Y}_{1}=+245+86.87 \mathrm{~A}(* \mathrm{P}<0.05)+27.25 \mathrm{~B}(* \mathrm{P}<0.05)+3.87 \mathrm{C}(\mathrm{P}>0.05)+10 \mathrm{AB}(\mathrm{P}>0.05)+2.25 \mathrm{AC}(\mathrm{P}>0.05)-2 \mathrm{BC}(\mathrm{P}>0.05)+18.37 \mathrm{~A}^{2}(* \mathrm{P}<0.05)$ $+9.12 \mathrm{~B}^{2}(\mathrm{P}>0.05)+3.87 \mathrm{C}^{2}(\mathrm{P}>0.05)(1)$

$\mathrm{Y}_{2}=+33.43+18.26 \mathrm{~A}(* \mathrm{P}<0.05)+4.48 \mathrm{~B}(* \mathrm{P}<0.05)+2.10 \mathrm{C}(* \mathrm{P}<0.05)+2.02 \mathrm{AB}(* \mathrm{P}<0.05)+1.52 \mathrm{AC}(* \mathrm{P}<0.05)-0.23 \mathrm{BC}(\mathrm{P}>0.05)$ $+4.16 \mathrm{~A}^{2}(* \mathrm{P}<0.05)-0.44 \mathrm{~B}^{2}(\mathrm{P}>0.05)+0.14 \mathrm{C}^{2}(\mathrm{P}>0.05)(2)$

$\mathrm{Y}_{3}=+0.19+0.01 \mathrm{~A}(* \mathrm{P}<0.05)-0.00 \mathrm{~B}(* \mathrm{P}<0.05)+0.01 \mathrm{C}(* \mathrm{P}<0.05)-0.00 \mathrm{AB}(\mathrm{P}>0.05)+0.00 \mathrm{AC}(* \mathrm{P}<0.05)-0.00 \mathrm{BC}(\mathrm{P}>0.05)$ $-0.00 \mathrm{~A}^{2}(\mathrm{P}>0.05)+0.00 \mathrm{~B}^{2}(* \mathrm{P}<0.05)+0.00 \mathrm{C}^{2}(\mathrm{P}>0.05)(3)$
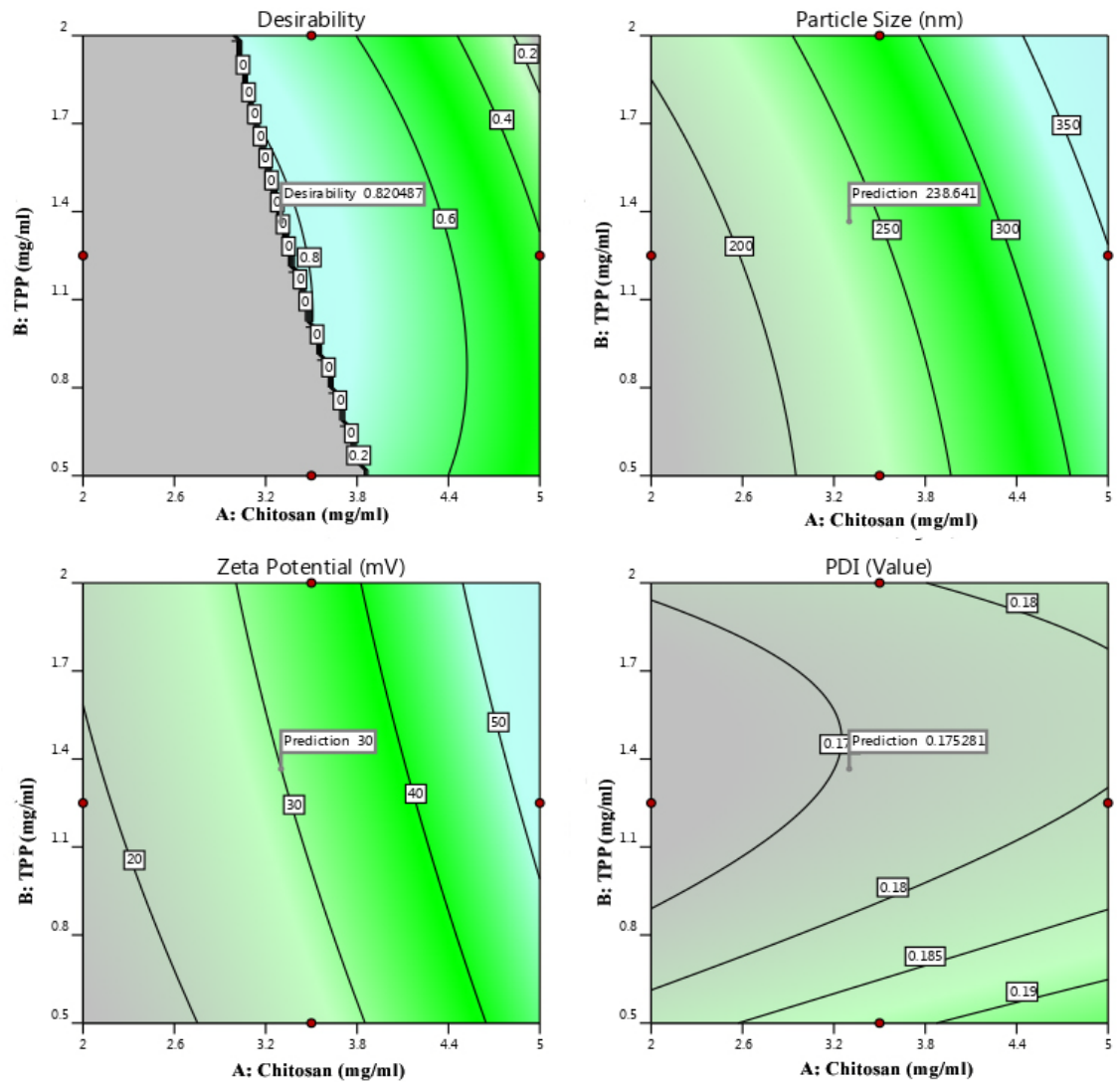

Fig. 1: 2D Response surface contour plots showing desirability between factors and responses (CSNPs)

Factor Coding: Actual
Particle Size $(n m)$
Design Points:
Above Surface
Below Surface
X1 $=$ A: Chitosan
X2 $=$ B: TPP
Actual Factor
C: Acetic acid $=0.200001$

3D Surface

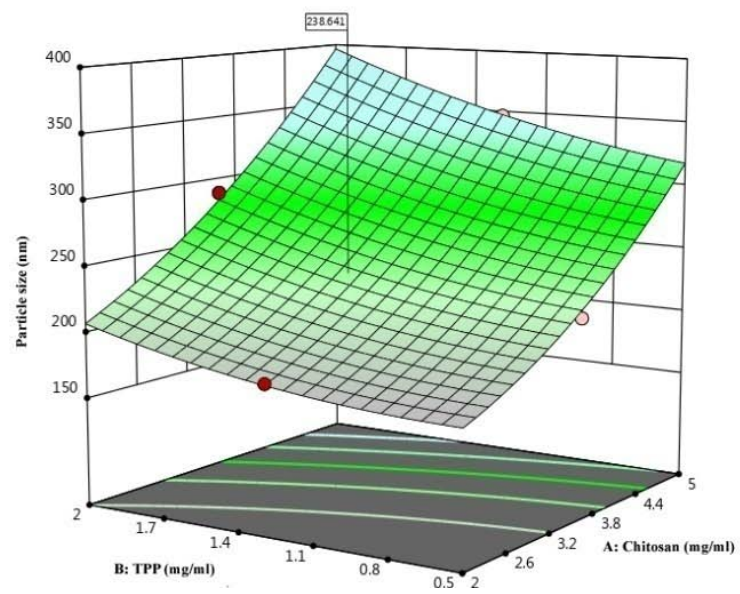

Fig. 2: 3D Response surface plots showing factors with particle size (CSNPs) 
Factor Coding: Actual

Zeta Potential (mV)

Design Points

- Above Surface

O Below Surface

$16.12 \square 62.21$

$x_{1}=A_{1} \cdot$ Chito

$\mathrm{X} 2=\mathrm{B}: \mathrm{TPP}$

Actual Factor

Actual Factor
C: Acetic acid $=0.200001$
3D Surface

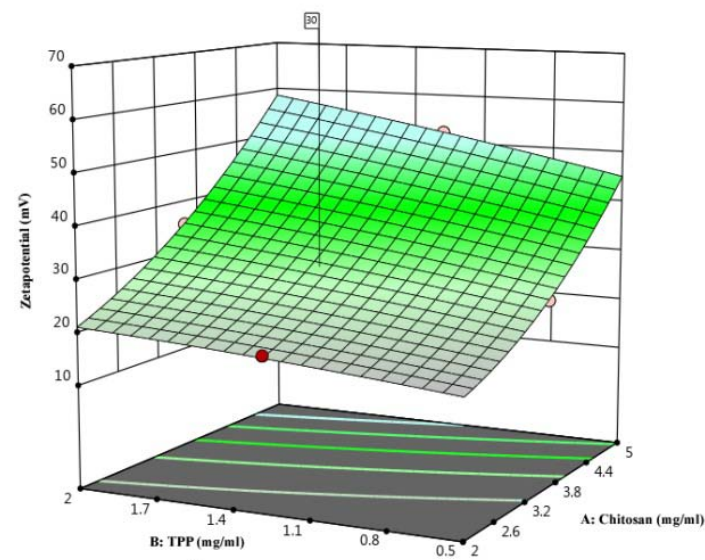

Fig. 3: 3D Response surface plots showing factors with zeta potential (CSNPs)

Factor Coding: Actual

PDI (Value)

Design Points:

- Above Surface

Below Surface

$0.173 \square \quad 0.232$

$\mathrm{X}_{1}=\mathrm{A} \cdot$ Chitosan

$\mathrm{X}_{2}=\mathrm{B}: \mathrm{TPP}$

Actual Factor

Actual factor
3D Surface

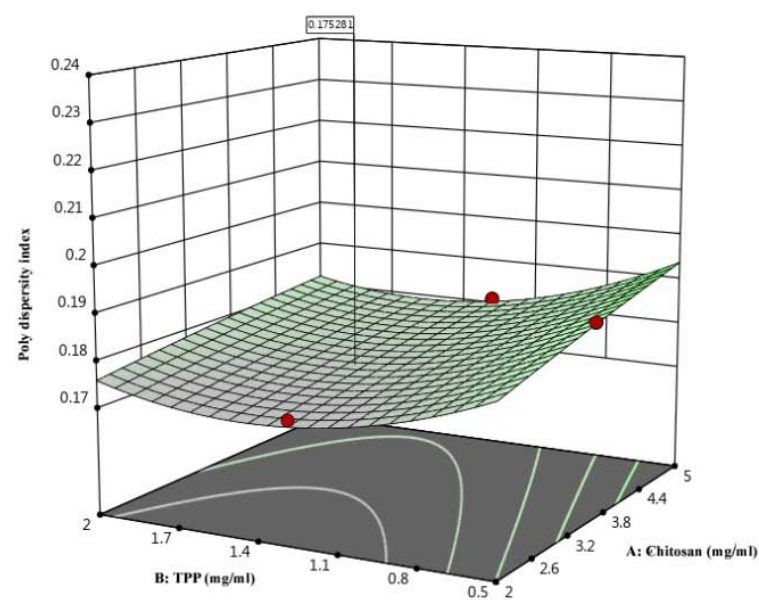

Fig. 4: 3D Response surface plots showing factors with PDI (Polydispersity index) (CSNPs)

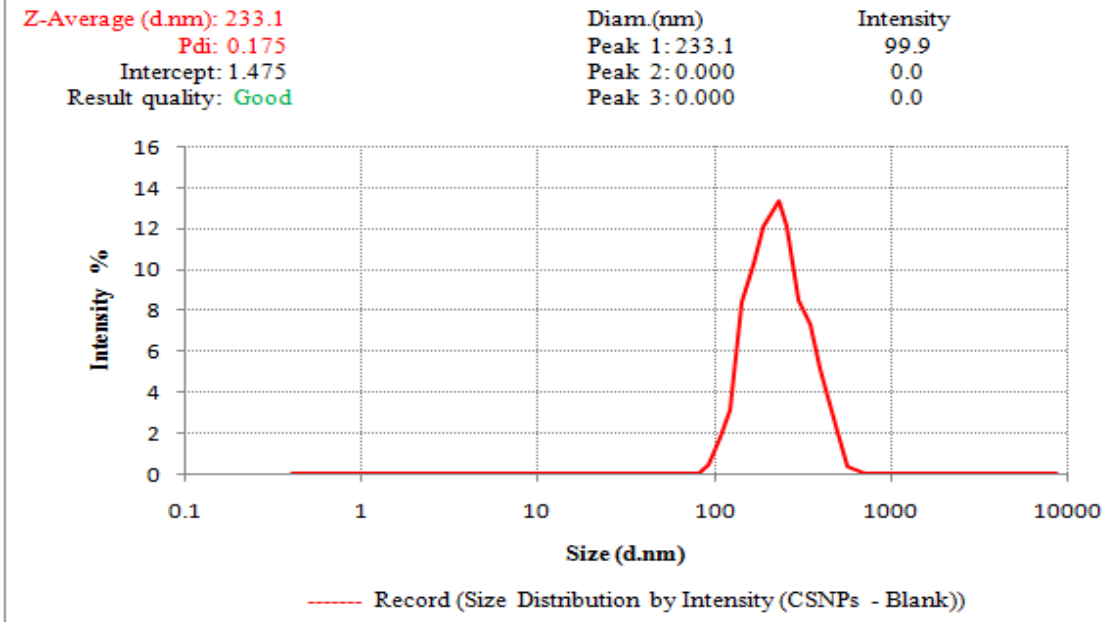

Fig. 5: Average particle size of optimized formulation (blank CSNPs) 
Table 7: Comparison of predicted and observed values of blank CSNPs

\begin{tabular}{|c|c|c|c|c|}
\hline \multirow[t]{2}{*}{ Confirmation location } & \multirow{2}{*}{$\begin{array}{l}\text { Chitosan (A) } \\
3.30\end{array}$} & \multirow{2}{*}{$\begin{array}{l}\text { TPP (B) } \\
1.36\end{array}$} & \multicolumn{2}{|c|}{ Acetic acid (C) } \\
\hline & & & 0.2 & \\
\hline Response & Predicted value & Observed value $(n=3)$ & Residuals & ${ }^{*}$ Bias \% \\
\hline Particle size $(\mathrm{nm})$ & 238.64 & $233 \pm 13.3$ & -5.64 & 2.42 \\
\hline Zeta potential (mV) & 30 & $32.01 \pm 3.11$ & 2.1 & -6.27 \\
\hline PDI & 0.175 & $0.171 \pm 0.004$ & -0.004 & 2.33 \\
\hline
\end{tabular}

* Bias \% = ((Predicted value - Observed value) * 100/Observed value *Data from each response for the observed values is presented in mean \pm SD ( $=3$ )

MCSNPs were formulated to optimize the concentration of methylprednisolone, stirring speed and temperature based on the dependent variables like particle size, zeta potential and encapsulation efficiency. Table 8 shows the results for responses. P-Values for the responses $\mathrm{y}_{1}, \mathrm{y}_{2}, \mathrm{y}_{3}$ was found to be $0.0084,0.0143$, and 0.0171 . Hence, the quadratic model is best fitted for all the responses with $* \mathrm{P}<0.05$. Table 9 shows a summary of the regression analysis of all the responses. Based on the desirability function, interaction effects between two factors and confirmation location was predicted using 2D contour and
3D response surface graphs shown in table 10 and fig. 6-10. Among the responses, $Y_{2}$ and $Y_{3}$ were set in maximize, whereas $Y_{1}$ in the minimized. Confirmation location for the optimized formulation was achieved at $\mathrm{A}=0.72 \mathrm{mg} / \mathrm{ml}, \mathrm{B}=531.24 \mathrm{rpm}, \mathrm{C}=27.90{ }^{\circ} \mathrm{C}$ with $\mathrm{Y}_{1}=$ $251.08 \mathrm{~nm}, \mathrm{Y}_{2}=46.43 \mathrm{mV}$ and $\mathrm{Y}_{3}=80.89 \%$ (Desirability-0.86). An overlay contour plot shown in fig. 10 explains the most supportive zone for all the responses. Observed values were found to be very close to the predicted values of confirmation location indicating the best optimization results using Box-Behnken Design.

Table 8: Optimization of methylprednisolone chitosan-based nanoparticles using ionic gelation technique: (Formulationmethylprednisolone CSNPs) $n=13$

\begin{tabular}{lll}
\hline Formulation code & Response-1 $\left(\mathbf{Y}_{\mathbf{1}}\right)$ particle size $(\mathbf{n m})$ & Response-2 $\left(\mathbf{Y}_{\mathbf{2}}\right)$ zeta potential $(\mathbf{m V})$ \\
\hline MCSNP-1 & $291.02 \pm 7.21$ & $43.96 \pm 3.54$ \\
MCSNP-2 & $260.13 \pm 5.64$ & $46.43 \pm 4.32$ \\
MCSNP-3 & $284.22 \pm 5.78$ & $38.17 \pm 2.11$ \\
MCSNP-4 & $219.04 \pm 6.32$ & $31.89 \pm 1.32$ \\
MCSNP-5 & $249.11 \pm 3.42$ & $37.14 \pm 2.44$ \\
MCSNP-6 & $245.21 \pm 4.56$ & $30.17 \pm 3.15$ \\
MCSNP-7 & $303.17 \pm 6.32$ & $22.19 \pm 3.54$ \\
MCSNP-8 & $312.16 \pm 2.43$ & $36.58 \pm 2.67$ \\
MCSNP-9 & $229.13 \pm 5.67$ & $34.16 \pm 2.89$ \\
MCSNP-10 & $264.11 \pm 7.54$ & $22.13 \pm 3.41$ \\
MCSNP-11 & $224.21 \pm 8.32$ & $20.11 \pm 1.83$ \\
MCSNP-12 & $267.14 \pm 3.56$ & $41.12 \pm 1.62$ \\
MCSNP-13 & $279.21 \pm 4.32$ & $24.49 \pm 2.43$ \\
\hline
\end{tabular}

*Data from each response is presented in mean $\pm \mathrm{SD}(\mathrm{n}=3)$
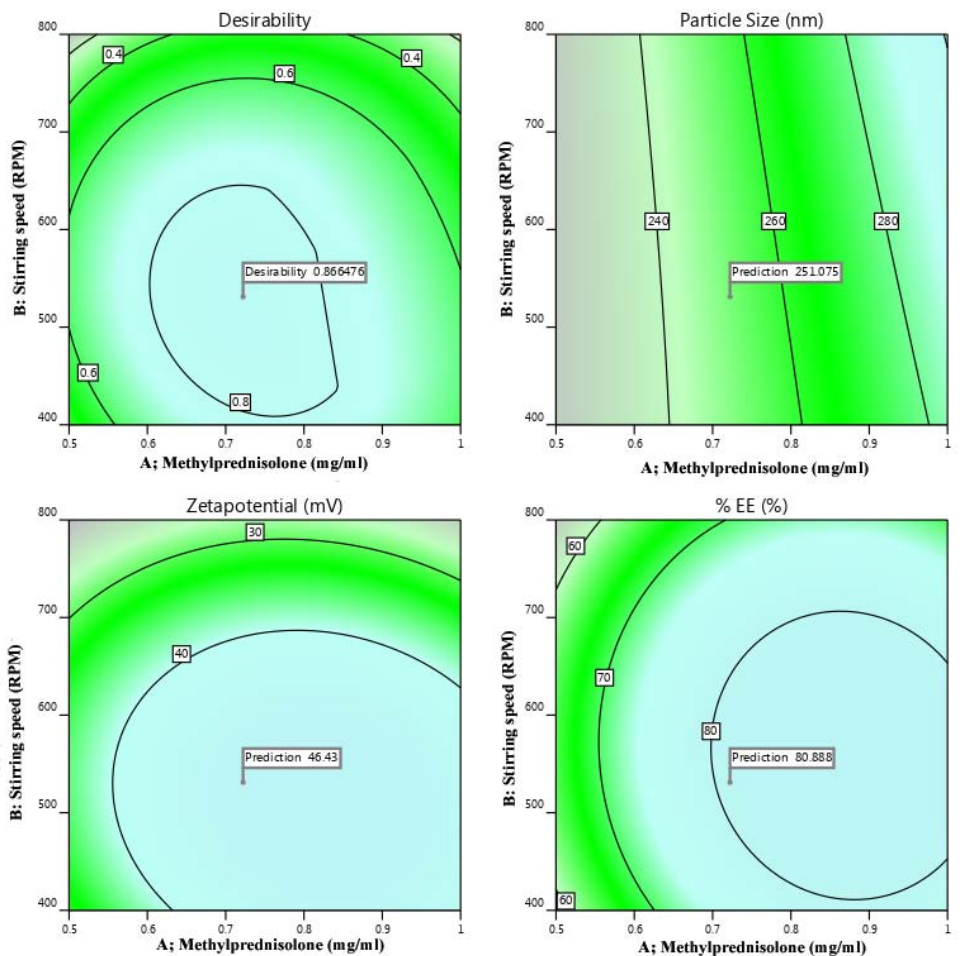

Fig. 6: 2D Response surface contour plots showing desirability between factors and responses (Methylprednisolone CSNPs) 
Table 9: Summary of regression analysis of the responses (methylprednisolone CSNPs)

\begin{tabular}{lllll}
\hline Quadratic model & $\mathbf{R}^{\mathbf{2}}$ & Adjusted R & SD & Adequate Precision \\
\hline Response-1 particle size (nm) & 0.98 & 0.57 & 6.16 & 16.67 \\
Response-2 zeta potential (mV) & 0.98 & 0.93 & 2.15 & 13.71 \\
Response-3 \% EE & 0.98 & 0.93 & 2.26 & 0.0084 \\
\hline
\end{tabular}

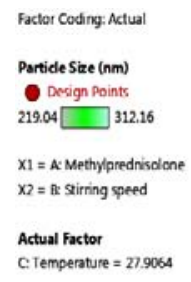

3D Surface

C. Temperature $=27.9064$

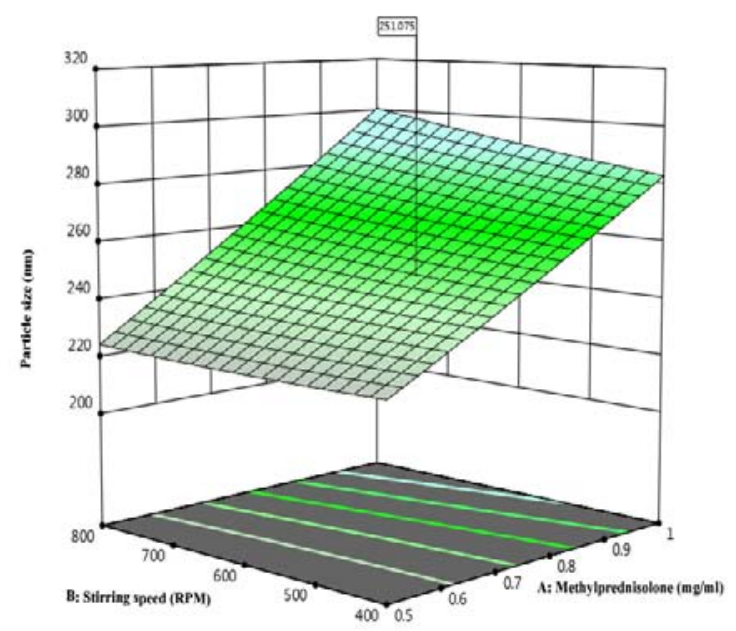

Fig. 7: 3D Response surface plots showing factors with particle size (MCSNPs)

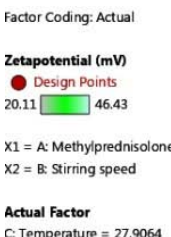

3D Surface

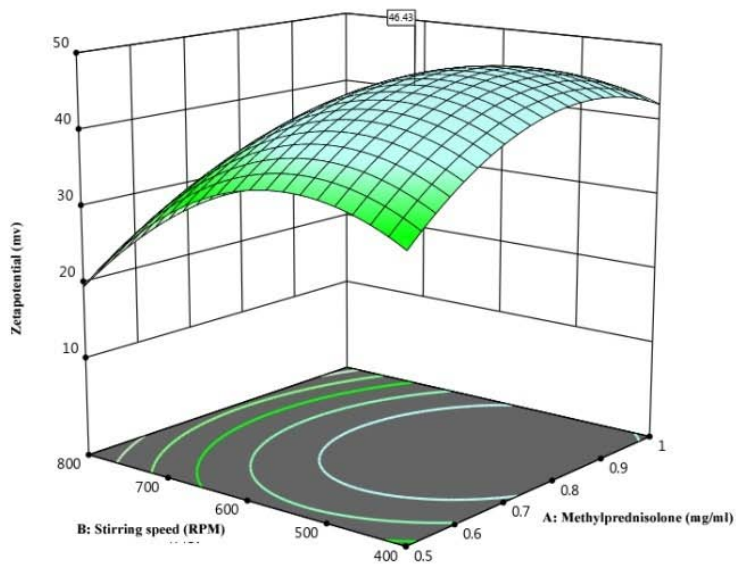

Fig. 8: 3D Response surface plots showing factors with zeta potential (MCSNPs)

Table 10: Comparison of predicted and observed values of MCSNPs

\begin{tabular}{|c|c|c|c|c|}
\hline \multirow[t]{2}{*}{ Confirmation location } & \multirow{2}{*}{$\begin{array}{l}\text { Methylprednisolone (mg/ml) } \\
0.72\end{array}$} & \multirow{2}{*}{$\begin{array}{l}\text { Stirring speed (RPM) } \\
531.24\end{array}$} & \multicolumn{2}{|c|}{ Temperature $\left({ }^{\circ} \mathrm{C}\right)$} \\
\hline & & & 27.90 & \\
\hline Response & Predicted value & Observed value $(n=3)$ & Residuals & ${ }^{*}$ Bias \% \\
\hline Particle size $(\mathrm{nm})$ & 251.08 & $243 \pm 2.33$ & -8.08 & 3.32 \\
\hline Zeta potential (mV) & 46.43 & $42.34 \pm 1.23$ & -4.09 & 9.65 \\
\hline$\% \mathrm{EE}$ & 80.89 & $79.3 \pm 7.2$ & -1.59 & 2.00 \\
\hline
\end{tabular}

$*$ Bias $\%=(($ Predicted value - Observed value $) * 100 /$ Observed value *Data from each response for the observed values is presented in mean \pm SD $(\mathrm{n}=3)$. 
Factor Coding: Actual

\%EE (\%)

$\underset{53.17 \square}{\square}{ }^{-1.12}$

$\mathrm{x}_{1}=\mathrm{A}$ : Methylprednisolon

$\mathrm{x} 2$ = $\mathrm{B}$ : Stiring speed

Actual Factor

C: Temperature $=27.9064$
3D Surface

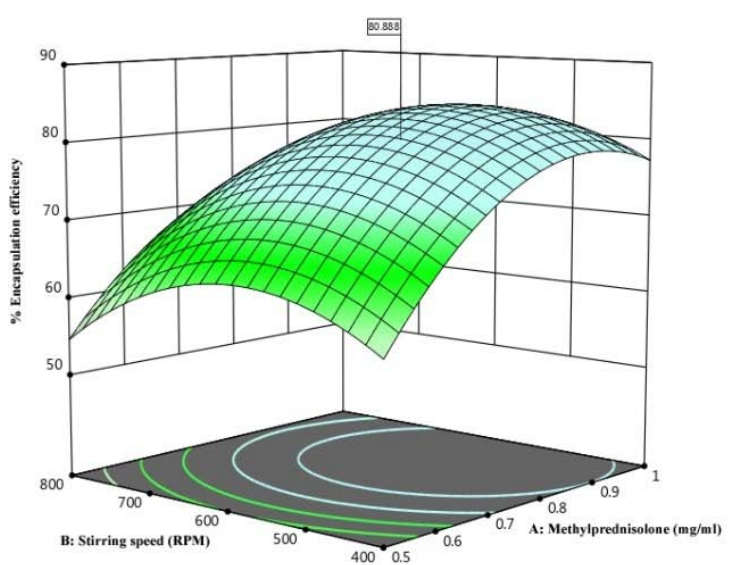

Fig. 9: 3D Response surface plots showing factors with encapsulation efficiency (MCSNPs)
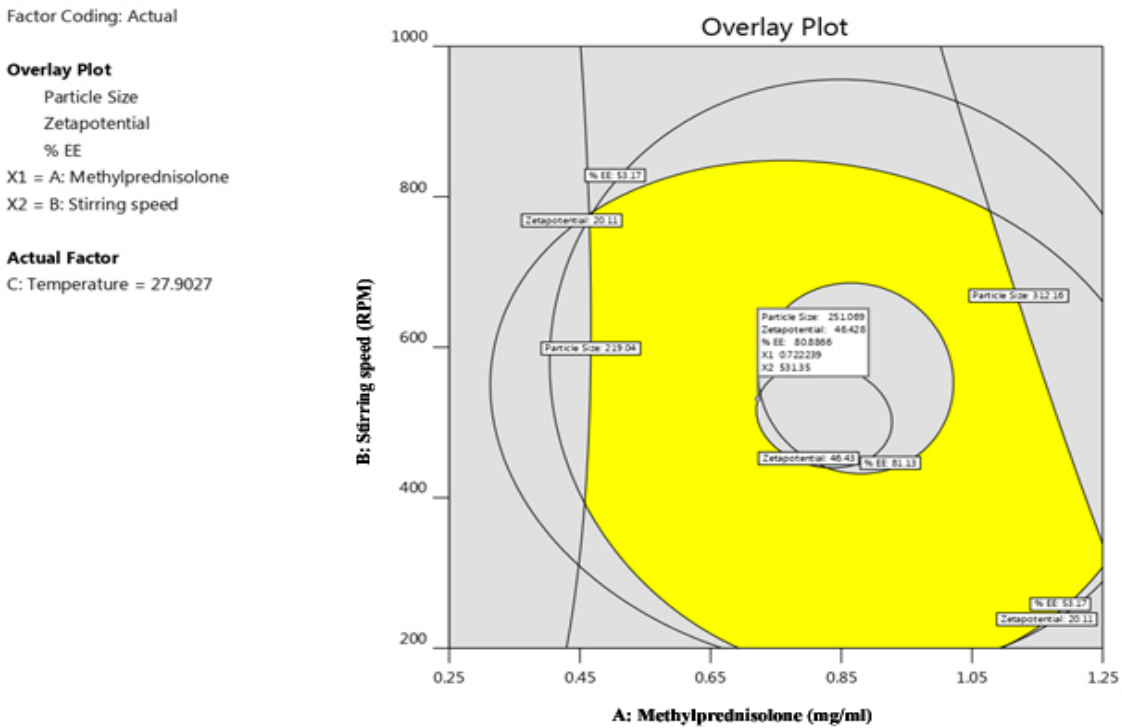

Fig. 10: Overlay contour plot for methylprednisolone CSNPs (MCSNPs)

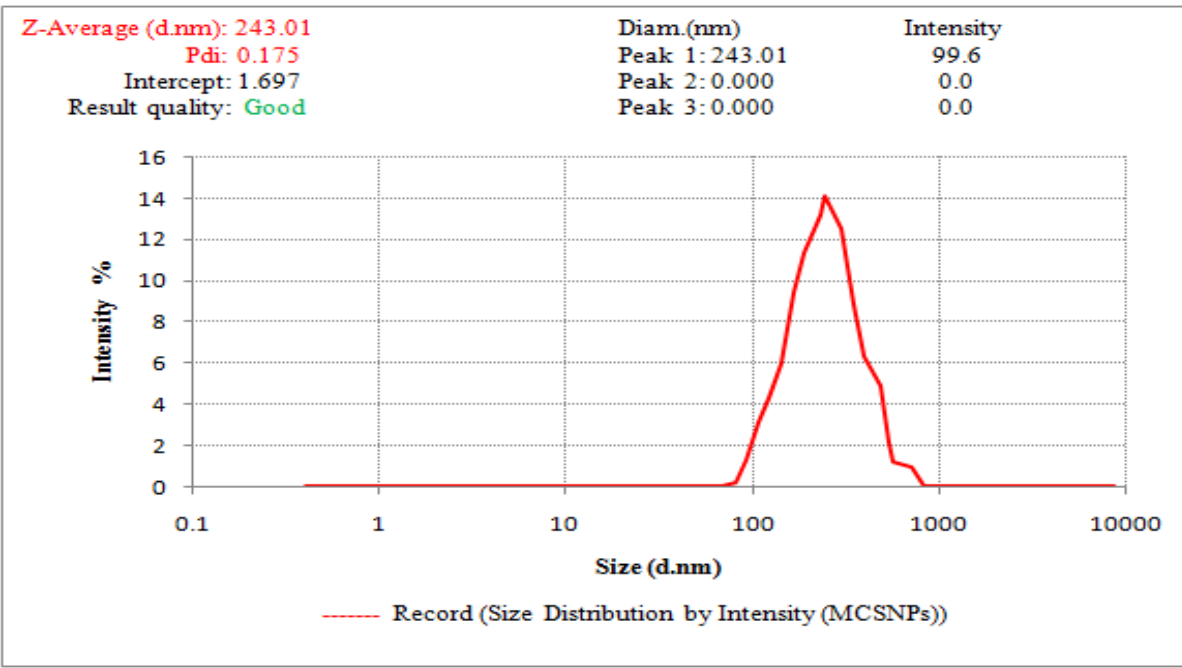

Fig. 11: Average particle size of optimized MCSNPs 


\section{Particle size}

There is an increase in particle size with increasing the concentration of methylprednisolone. Particle size was found to be increased with an increase in stirring speed up to $600 \mathrm{rpm}$ and decreased thereafter which maybe because of the prevalence of high shearing rates that destroys the repulsive forces leading to aggregation $[29,30]$. Particle size decreased linearly from $312.16 \pm 2.43$ to $219.04 \pm 6.32$ with an increase in temperature which is shown in 3D response surface graphs (fig. 7). Polynomial equation with an intercept and coded factors is as follows-

$$
\begin{aligned}
\mathrm{Y}_{1}=+260.13+34.12 \mathrm{~A} & (* \mathrm{P}<0.05)+4.28 \mathrm{~B}(\mathrm{P}>0.05) \\
& -10.90 \mathrm{C}(* \mathrm{P}<0.05)+4.26 \mathrm{AB}(\mathrm{P}>0.05) \\
& -0.44 \mathrm{AC}(\mathrm{P}>0.05)+0.73 B C(\mathrm{P}>0.05) \\
& +1.00 \mathrm{~A}^{2}(\mathrm{P}>0.05)+0.74 \mathrm{~B}^{2}(\mathrm{P}>0.05) \\
& +4.01 \mathrm{C}^{2}(\mathrm{P}>0.05)(4)
\end{aligned}
$$

From the equation, independent variables like $\mathrm{A}$ and $\mathrm{C}$ were significant as the p-value is less than 0.05 . The observed value of particle size for the confirmation location was found to be $243 \pm 2.33$ and the results were given in table 10 and fig. 11.

\section{\% Encapsulation efficiency (EE)}

\% EE of all the MCSNPs ranged from $53.17 \pm 1.36$ to $81.12 \pm 3.11 \%$. Polynomial equation with an intercept and coded factors is as follows-

$$
\begin{aligned}
\mathrm{Y}_{3}=+81.12+7.68 \mathrm{~A}( & * \mathrm{P}<0.05)-2.61 \mathrm{~B}(* \mathrm{P}<0.05) \\
& +3.27 \mathrm{C}(* \mathrm{P}<0.05)-0.86 \mathrm{AB}(\mathrm{P}>0.05) \\
& +0.91 \mathrm{AC}(\mathrm{P}>0.05)-0.52 \mathrm{BC}(\mathrm{P}>0.05) \\
& -8.89 \mathrm{~A}^{2}(* \mathrm{P}<0.05)-7.91 \mathrm{~B}^{2}(* \mathrm{P}<0.05) \\
& -3.2 \mathrm{C}^{2}(\mathrm{P}>0.05)(5)
\end{aligned}
$$

From equation 5 , the independent variables like $\mathrm{A}, \mathrm{B}, \mathrm{C}, \mathrm{A}^{2}$ and $\mathrm{B}^{2}$ was significant as the p-value is less than 0.05 . Encapsulation efficiency was found to be increased up to $0.75 \mathrm{mg} / \mathrm{ml}$ concentration of methylprednisolone and decreased thereafter. Further, the increase in methylprednisolone concentration lead to a decrease in $\% \mathrm{EE}$, which may be because of the precipitation of chitosan molecules in the dispersion. \% EE was found to be increased up to $600 \mathrm{rpm}$ and decreased thereafter which may be due to the prevalence of high shearing rates that destroys the repulsive forces leading to aggregation $[29,30]$. These results were shown in 3D response surface graph-fig. 9. Observed $\% \mathrm{EE}$ of the optimized batch was found to be $79.3 \pm 7.2$ with particle size $243 \pm 2.33$.

\section{Zeta potential}

Zeta potential of all MCSNPs ranged from $21.31 \pm 3.36$ to $43.21 \pm 1.79$ $\mathrm{mV}$. Polynomial equation with intercept and coded factors is as follows-

$$
\begin{aligned}
\mathrm{Y}_{2}=+46.43+3.07 \mathrm{~A}( & * \mathrm{P}<0.05)-8.43 \mathrm{~B}(* \mathrm{P}<0.05) \\
& -0.37 \mathrm{C}(\mathrm{P}>0.05)-1.93 \mathrm{AB}(\mathrm{P}>0.05) \\
& -0.03 \mathrm{AC}(\mathrm{P}>0.05)+0.40 \mathrm{BC}(\mathrm{P}>0.05) \\
& -6.67 \mathrm{~A}^{2}(* \mathrm{P}<0.05)-9.65 \mathrm{~B}^{2}(* \mathrm{P}<0.05) \\
& -5.5 \mathrm{C}^{2}(* \mathrm{P}<0.05)(6)
\end{aligned}
$$

From equation 6, independent variables like $\mathrm{A}, \mathrm{B}, \mathrm{A}^{2}, \mathrm{~B}^{2}$ and $\mathrm{C}^{2}$ were significant as the $\mathrm{p}$-value is less than 0.05 . Zeta potential was mainly affected by stirring speed and temperature. At higher speeds and temperature a decrease in the viscosity of chitosan leads to structural instability decreasing zeta potential [31]. Observed value of zeta potential for the confirmation location was found to be $+43.34 \pm 1.23$. This positive surface charge leads to interaction with mucin and has the characteristics of mucoadhesion [32].

\section{Morphology}

Scanning electron microscopy reveals that there is an increase in the particle size of MCSNPs when compared to CSNPs. From the micrographs (fig. 12), it was evident that particles were rough in texture with the nearly spherical shape.

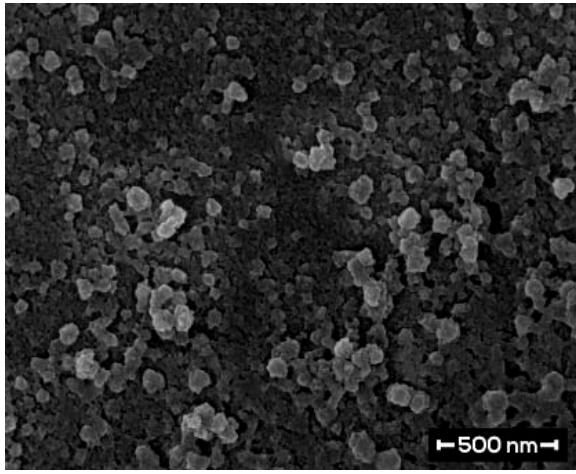

A

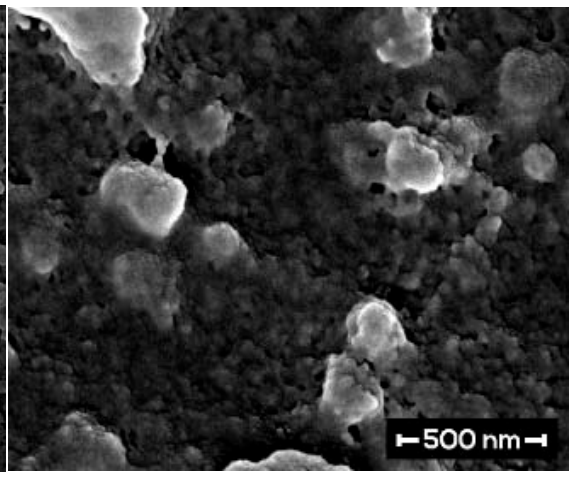

B

Fig. 12: SEM photographs of A) Optimized CSNPs, B) Optimized MCSNPs (mean \pm SEM), $n=3$

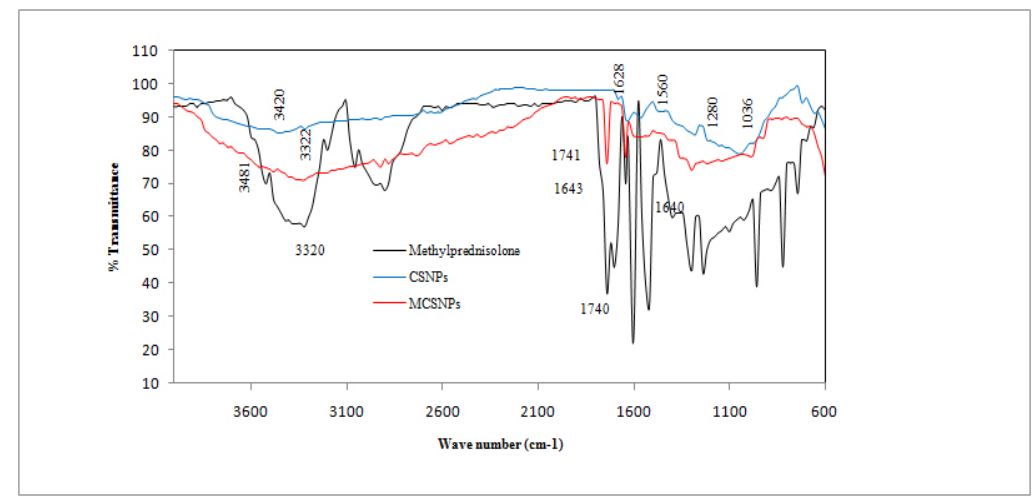

Fig. 13: FT-IR of methylprednisolone (pure drug), optimized blank chitosan nanoparticles (CSNPS), optimized methylprednisolone nanoparticles (MCSNPS) 


\section{Differential scanning calorimetry}

Broad endothermic peak was observed at $236.1{ }^{\circ} \mathrm{C}$ for methylprednisolone corresponding to its melting point shown in fig. 14. CSNPs experienced two endothermic peaks at $56.8^{\circ} \mathrm{C}$ and 330.2 ${ }^{\circ} \mathrm{C}$, in relation to evaporation of water and degradation of chitosan respectively [36, 37]. Endothermic peak of methylprednisolone was shifted from $236.1{ }^{\circ} \mathrm{C}$ to $280.3{ }^{\circ} \mathrm{C}$ in MCSNPs indicating superior thermal stability of methylprednisolone.

\section{X-ray diffraction}

Powdered X-ray diffraction patterns for the pure methylprednisolone and optimized MCSNPs were shown in fig. 15. Pure methylprednisolone showed larger Lin (counts) when compared to optimized MCSNPs. Fewer intensities of methylprednisolone in MCSNPs indicates that the drug is in disordered crystalline or in amorphous form. This study indicates the improvement of solubility of methylprednisolone in MCSNPs [38].

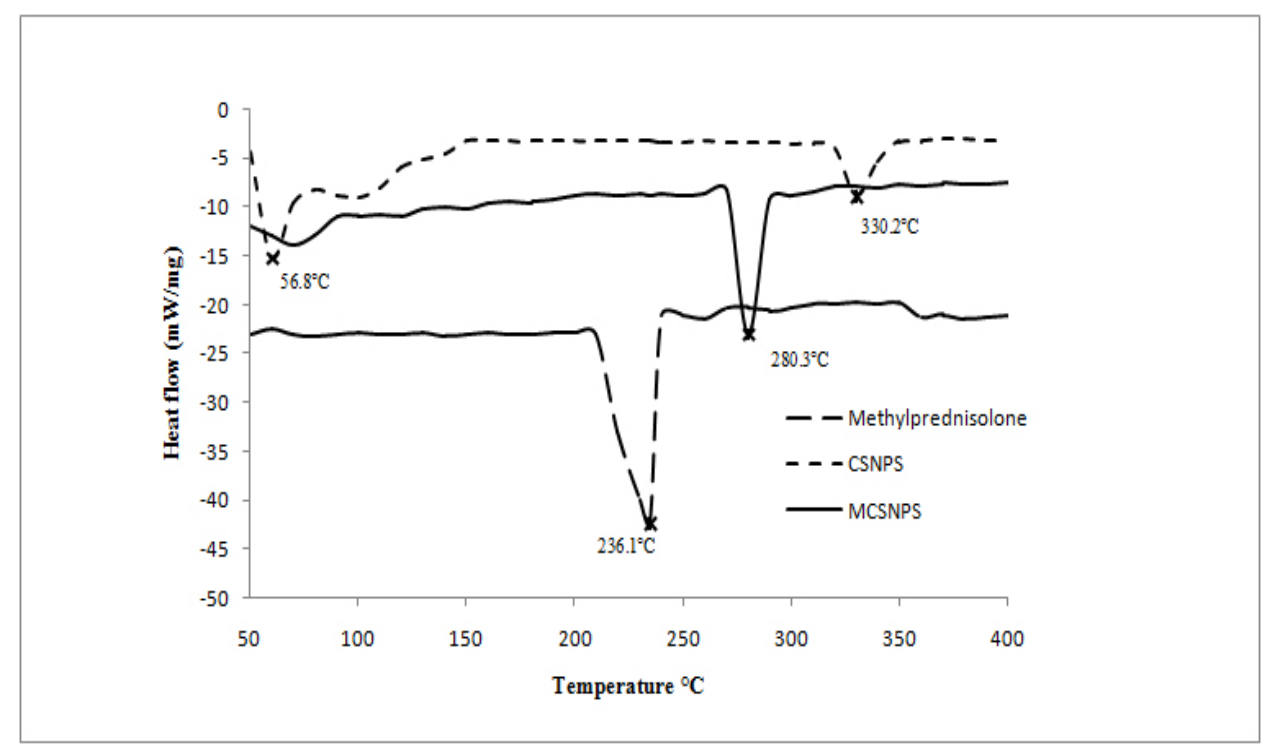

Fig. 14: DSC of methylprednisolone (pure drug), blank chitosan nanoparticles (CSNPs), Optimized methylprednisolone nanoparticles (MCSNPs)

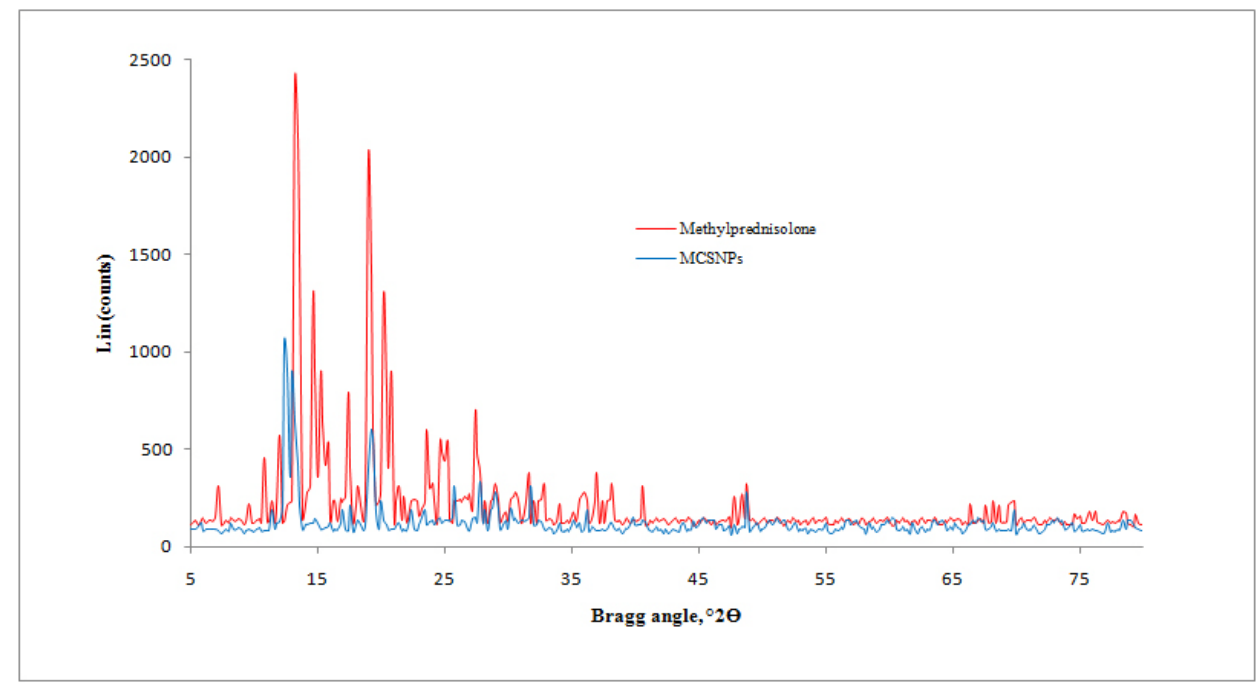

Fig. 15: PXRD of methylprednisolone and optimized methylprednisolone nanoparticles (MCSNPS)

\section{In vitro drug release studies}

Cumulative drug release for optimized MCSNPs was conducted for $24 \mathrm{~h}$ in phosphate buffer and simulated colonic fluids (SCF) as shown in table 11 and fig. 16. Cumulative drug release of methylprednisolone CSNPs in phosphate buffer pH 7.4, SCF pH 7, SCF pH 6 (Fed state), SCF pH 7.8 (Fasted state) was found to be $99.97 \pm 3.02,99.07 \pm 3.51,96.63 \pm 1.53$ and $98.63 \pm 2.52 \%$ respectively.

In SCF pH 6 (Fed state) over 95\% of the drug was released within $11 \mathrm{H}$, which may be due to the solubility of chitosan in acidic and slightly acidic $\mathrm{pH}$ [39]. From the results, it was found that over $99 \%$ of the drug was released in $24 \mathrm{~h}$ in phosphate buffer $\mathrm{pH} 7.4$ and SCF pH 7 and SCF pH 7.8 (Fasted state) which was found to be the best when compared to the drug release in other SCF pH 6 (Fed state).

Results were fitted with various kinetic models as shown in table 12 . Korsemeyer-peppas was found to be the best-fitted model with a mechanism of drug release as non-fickian diffusion with $\mathrm{n}$ value ranging from $0.64-0.82$. 
Table 11: In vitro drug release studies of methylprednisolone CSNPs

\begin{tabular}{lllll}
\hline Time (H) & $\begin{array}{l}\text { \% Drug release } \\
\text { (phosphate buffer pH 7.4) }\end{array}$ & $\begin{array}{l}\text { \% Drug release simulated } \\
\text { colonic fluid-pH 7 }\end{array}$ & $\begin{array}{l}\text { \% Drug release simulated } \\
\text { colonic fluid (Fed State)-pH 6 }\end{array}$ & $\begin{array}{l}\text { \% Drug release simulated colonic } \\
\text { fluid (Fasted State)-pH 7.8 }\end{array}$ \\
\hline 1 & $11.67 \pm 5.01$ & $13.93 \pm 0.90$ & $14.73 \pm 1.53$ & $10.63 \pm 2.52$ \\
2 & $25.13 \pm 2.84$ & $23.17 \pm 3.51$ & $28.17 \pm 1.69$ & $13.77 \pm 2.04$ \\
3 & $27.93 \pm 2.81$ & $27.07 \pm 2.61$ & $34.83 \pm 0.68$ & $17.13 \pm 2.73$ \\
4 & $32.43 \pm 1.82$ & $34.80 \pm 2.16$ & $38.13 \pm 1.53$ & $23.10 \pm 3.73$ \\
5 & $35.93 \pm 1.62$ & $37.80 \pm 2.76$ & $42.80 \pm 3.50$ & $34.00 \pm 3.77$ \\
6 & $43.33 \pm 1.59$ & $42.17 \pm 3.51$ & $59.93 \pm 1.58$ & $38.97 \pm 2.63$ \\
7 & $47.73 \pm 1.75$ & $44.73 \pm 2.01$ & $65.47 \pm 3.44$ & $56.53 \pm 1.57$ \\
8 & $51.03 \pm 2.73$ & $52.47 \pm 3.66$ & $76.07 \pm 1.37$ & $53.53 \pm 2.52$ \\
9 & $58.23 \pm 2.81$ & $54.60 \pm 2.43$ & $79.63 \pm 1.53$ & $62.73 \pm 1.66$ \\
10 & $63.13 \pm 2.94$ & $63.73 \pm 4.98$ & $96.70 \pm 2.82$ & $68.10 \pm 2.71$ \\
11 & $66.73 \pm 2.63$ & $65.37 \pm 3.51$ & - & $74.93 \pm 2.52$ \\
12 & $72.13 \pm 2.11$ & $78.07 \pm 2.61$ & - & $88.63 \pm 2.53$ \\
16 & $84.13 \pm 2.72$ & $86.40 \pm 4.46$ & - & $98.63 \pm 2.52$ \\
24 & $99.97 \pm 3.02$ & $99.07 \pm 3.51$ & & \\
\hline
\end{tabular}

$\left({ }^{*}\right.$ Data from each profile is presented in mean $\left.\pm \operatorname{SD}(n=3)\right)$

Table 12: Drug release kinetics of optimized MCSNPs

\begin{tabular}{|c|c|c|c|c|c|}
\hline \multirow[t]{2}{*}{ MCSNPs } & \multirow[t]{2}{*}{ Zero-order $\left(R^{2}\right)$} & \multirow[t]{2}{*}{ First-order $\left(R^{2}\right)$} & \multirow[t]{2}{*}{ Higuchi $\left(R^{2}\right)$} & \multicolumn{2}{|c|}{ Korsmeyer peppas } \\
\hline & & & & $\left(R^{2}\right)$ & (n) \\
\hline MCSNPs-PBS (pH 7.4) & 0.93 & 0.73 & 0.98 & 0.98 & 0.67 \\
\hline MCSNPs-SCF FED (pH 6) & 0.98 & 0.83 & 0.94 & 0.98 & 0.76 \\
\hline MCSNPs-SCF FASTED (pH 7.8) & 0.92 & 0.93 & 0.94 & 0.97 & 0.82 \\
\hline MCSNPs-SCF (pH 7) & 0.92 & 0.89 & 0.97 & 0.99 & 0.64 \\
\hline
\end{tabular}

$(*$ Data from each parameter is presented in replication $(n=3)$ )

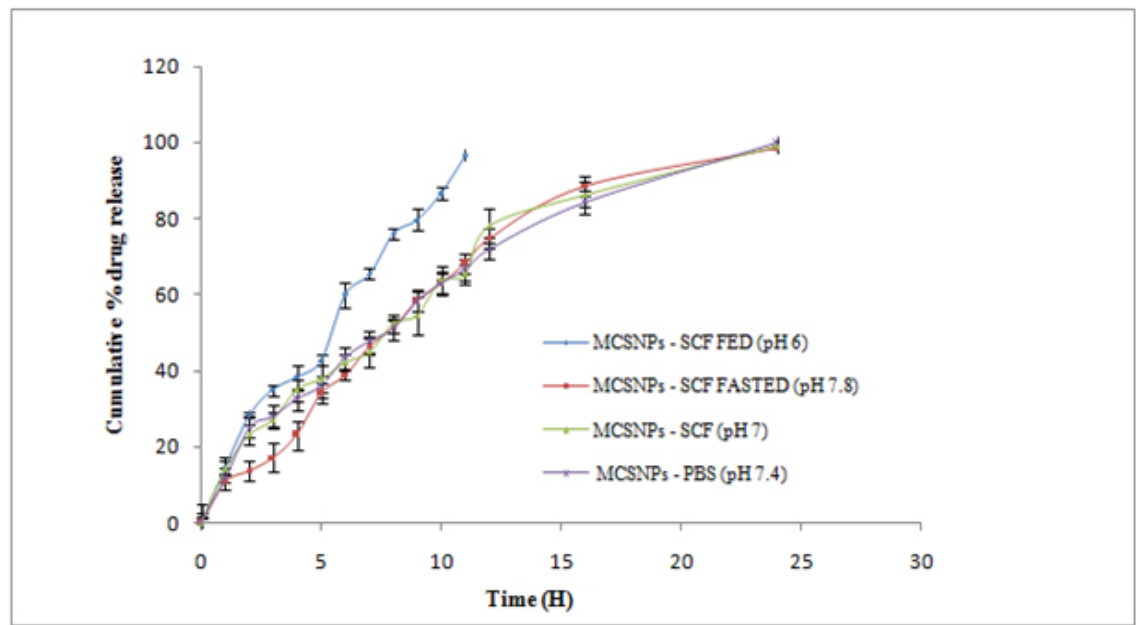

Fig. 16: Cumulative \% drug release of optimized methylprednisolone nanoparticles (MCSNPS) in various fluids (SCF-simulated colonic fluid, PBS-phosphate buffer), (*Data from each profile is presented in mean \pm SD $(n=3)$ )

\section{CONCLUSION}

Methylprednisolone chitosan-based nanoparticles were successfully optimized using Design-Expert software by applying BBD and RSM Amorphous nature and thermal stability of MCSNPs were confirmed using PXRD and DSC. Encapsulation efficiency of MCSNPs was nearly $80 \%$ and the formation of hydrogen bonds between the chitosan and methylprednisolone was confirmed using FT-IR. The prepared nanostructures showed an extended-release of MCSNPs in simulated colonic fluids with improved bioavailability. Though the results seem to be successful in SCF in vitro, further research should be carried out to coat MCSNPs using $\mathrm{pH}$-sensitive polymers to decrease the solubility of chitosan in upper GIT.

\section{ACKNOWLEDGMENT}

The authors are heartily thankful to SP Accure Labs and Dr. M. Gobinath M. Pharm, Ph. D., Principal, Ratnam Institute of Pharmacy for permitting to do the work and providing all the necessary facilities.

\section{FUNDING}

Nil

\section{AUTHORS CONTRIBUTIONS}

Authors declare that the work done by the names mentioned in the article and all the liabilities and claims related to the content of the article will be borne by the authors.

\section{CONFLICT OF INTERESTS}

The authors declare that no conflict of interest associated with this work.

\section{REFERENCES}

1. Malchow H, Ewe K, Brandes JW. European cooperative crohn's disease study (ECCDS): results of drug treatment Gastroenterology 1984;86:249-66. 
2. Gross V, Andus T, Caesar I, Bischoff SC, Lochs H, Tromm A, et al. Oral pH-modified release budesonide versus 6methylprednisolone in active crohn's disease. German/ Austrian budesonide study group. Eur J Gastroenterol Hepatol 1996;8:905-9.

3. Jagdale S, Chandekar A. Site targeted press coated delivery of methylprednisolone using eudragit rs 100 and chitosan for treatment of colitis. Recent Pat Antiinfect Drug Discovery 2011;11:32-43.

4. Modigliani R, Mary JY, Simon JF. Clinical, biological, and endoscopic picture of attacks of Crohn's disease. Evolution on prednisolone. Groupe d'Etude Therapeutique des Affections Inflammatoires Digestives. Gastroenterology 1990;98:811-8.

5. Campieri M, Ferguson A, Doe W. Oral budesonide is as effective as oral prednisolone in active Crohn's disease. Gut 1997;41:209-14.

6. Bar Meir S, Chowers Y, Lavy A, Lavy A, Abramovitch D, Sternberg $\mathrm{A}$, et al. Budesonide versus prednisone in the treatment of active crohn's disease. The israeli budesonide study group. Gastroenterology 1998;115:835-40.

7. Pravin Patel D, Sushma Singh. Chitosan: a multifacet polymer. Int J Curr Pharm Res 2015;7:21-8.

8. Younes I, Rinaudo M. Chitin and chitosan preparation from marine sources. structure, properties, and applications. Mar Drugs 2015;13:1133-74.

9. Yi H, Wu LQ Bentley WE, Ghodssi R, Rubloff GW, Culver JN, et al. Biofabrication with chitosan. Biomacromolecules 2005;6:2881-94.

10. Tiyaboonchai W. Chitosan nanoparticles: a promising system for drug delivery. Naresuan University J 2003;11:51-66.

11. Lin $\mathrm{Wu}$, Mingyu Chen. albumin-based nanoparticles as methylprednisolone carriers for targeted delivery towards the neonatal Fc receptor in glomerular podocytes. Int J Mol Med 2017;39:851-60.

12. Zhang L, Li Y, Wang C. Synthesis of methylprednisolone loaded ibuprofen modified inulin based nanoparticles and their application for drug delivery. Mater Sci Eng C 2014;42:111-5.

13. Hwang J, Rodgers K, Oliver JC. $\alpha$-Methylprednisolone conjugated cyclodextrin polymer-based nanoparticles for rheumatoid arthritis therapy. Int J Nanomed 2008;3:359-71.

14. Goldstein J, Newbury DE, Joy DC, Lyman CE, Echlin P, Lifshin $\mathrm{E}$, et al. Scanning electron microscopy and x-ray microanalysis. $3^{\text {rd }}$ ed. Springer; 2003. p. 21-60.

15. Victor Olaitan, Cheng Shu Chaw. Desolvation conditions for the production of sulfasalazine based albumin nanoparticles: physical properties. Pharm Front 2019;1:1-15.

16. Preet Kaur S, Rao R, Hussain A, Khatkar S. Preparation and characterization of rivastigmine loaded chitosan nanoparticles. J Pharm Sci Res 2011;3:1227-32.

17. Shevchenko EV, Talapin DV, Kotov NA, O'Brien S, Murray CB. Structural diversity in binary nanoparticle superlattices. Nature 2006:439:55-9.

18. Dubes A, Parrot Lopez H, Abdelwahed W, Degobert G, Fessi H, Shahgaldian P, Coleman AW. Scanning electron microscopy and atomic force microscopy imaging of solid lipid nanoparticles derived from amphiphilic cyclodextrins. Eur J Pharm Biopharm 2003;55:279-82.

19. Patel R, Gajra B. Ganciclovir loaded chitosan nanoparticles: preparation and characterization. J Nanomed Nanotechnol 2016;7:1000411.

20. Ahdyani R, Novitasari L. Formulation and characterization of timolol maleate-loaded nanoparticles gel by ionic gelation method using chitosan and sodium alginate. Int J Appl Pharm 2019;11:48-54.

21. Ray M, Pal K, Anis A, Banthia A. Development and characterization of chitosan-based polymeric hydrogel membranes. Des Monomers Polym 2010;13:193-206.
22. Qi L, Xu Z, Jiang X, Hu C, Zou X. Preparation and antibacterial activity of chitosan nanoparticles. Carbohydr Res 2004;339:2693-700.

23. Dash S, Murthy PN, Nath L, Chowdhury P. Kinetic modeling on drug release from controlled drug delivery systems. Acta Pol Pharm 2010;67:217-23.

24. Marasini N, Yan YD, Poudel BK, Choi HG, Yong CS, Kim JO. Development and optimization of self-nano emulsifying drug delivery system with enhanced bioavailability by boxbehnken design and desirability function. J Pharm Sci 2012;101:4584-96

25. Ferreira SC, Bruns RE, Ferreira HS, Matos GD, David JM, Brandao GC, et al. Box-behnken design: an alternative for the optimization of analytical methods. Anal Chim Acta 2007;597:179-86.

26. Gan Q, Wang T, Cochrane C, Mccarron P. Modulation of surface charge, particle size and morphological properties of chitosanTPP nanoparticles intended for gene delivery. Colloids Surf B Biointerfaces 2005;44:65-73.

27. Grenha A, Seijo B, Remunan Lopez C. Microencapsulated chitosan nanoparticles for lung protein delivery. Eur J Pharm Sci 2005;25:427-37.

28. Liu H, Gao C. Preparation and properties of ionically crosslinked chitosan nanoparticles. Polym Adv Technol 2009;20:613-9.

29. Tsai ML, Bai SW, Chen RH. Cavitation effects versus stretch effects resulted in different size and polydispersity of ionotropic gelation chitosan-sodium tripolyphosphate nanoparticle. Carbohydr Polym 2008;71:448-57.

30. Carvalho EL, Grenha A, Remunan Lopez C, Alonso MJ, Seijo B. Mucosal delivery of liposome-chitosan nanoparticle complexes. Meth Enzymol 2009;465:289-312.

31. Rampino A, Borgogna M. Chitosan nanoparticles: preparation, size evolution and stability. Int J Pharm 2013;455:219-28.

32. Seong Chul Hong, Seung Yup Yo. Chitosan-based multifunctional platforms for local delivery of therapeutics. Mar Drugs 2017;15:60.

33. Sofia Papadimitriou A, Dimtrios Bikiaris M. Chitosan nanoparticles loaded with dorzolamide and pramipexole. Carbohydrate Polymers 2008;73:44-54.

34. Vino AB, Ramasamy $P$, Shanmugam V, Shanmugam A Extraction, characterization and in vitro antioxidative potential of chitosan and sulfated chitosan from cuttlebone of sepia aculeate orbigny, 1848. Asian Pac J Trop Biomed 2012;2:S334S341.

35. Swathi J, Apoorva C. Optimization of chitosan and cellulose acetate phthalate controlled delivery of methylprednisolone for treatment of inflammatory bowel disease. Adv Pharm Bull 2017;7:203-13

36. Kittur FS, Prashanth KVH, Sankar KU, Tharanathan RN Characterization of chitin, chitosan and their carboxymethyl derivatives by differential scanning calorimetry. Carbohydr Polym 2002;49:185-93

37. Gazori T, Khoshayand MR, Azizi E, Yazdizade P, Nomani A, Haririan I. Evaluation of alginate/chitosan nanoparticles as antisense delivery vector: formulation, optimization and in vitro characterization. Carbohydr Polym 2009;77:599-606.

38. Wang W, Zhu R, Xie Q, Li A, Xiao Y, Li K, et al. Enhanced bioavailability and efficiency of curcumin for the treatment of asthma by its formulation in solid lipid nanoparticles. Int J Nanomed 2012;7:3667-77.

39. Avadi MR, Sadeghi AM, Mohammadpour M. Preparation and characterization of insulin nanoparticles using chitosan and Arabic gum with ionic gelation method. Nanomedicine 2010;6:58-63. 